\title{
APROXIMAÇÕES CONCEITUAIS DO CENÁRIO DE VIOLÊNCIA QUE A PROPOSTA DE UMA CULTURA DA PAZ PRETENDE ENFRENTAR EM DEFESA DOS DIREITOS DA PERSONALIDADE
}

\author{
Giovanna Back* \\ Ivan Dias da Motta**
}

\section{RESUMO}

Busca-se, no presente analisar a cultura da paz e como instrumento de prevenção e combate da violência, em especial no ambiente escolar, a partir do pleno desenvolvimento da personalidade pela educação formadora e emancipatória. Nesse sentido, pelo método dedutivo, objetiva-se entender a relação bergsoniana entre memória e corpo, pela formação de comportamentos sociais pelo hábito e o uso do biopoder no desvio da educação-formação para a educação-treinamento, na sociedade de controle e a validação da hipótese de que a cultura da paz seria um instrumento positivo para abertura de espaço à percepção racional e revestida de afetação e à intuição.

PALAVRAS-CHAVE: Memória-corpo. Biopoder. Violência. Intuição. Cultura da paz.

\section{CONCEPTUAL APPROACHES TO THE SCENARIO OF VIOLENCE THAT THE PROPOSAL OF A CULTURE OF PEACE INTENDS TO FACE}

\begin{abstract}
At present, we seek to analyze the culture of peace as instrument to prevent and combat violence, especially in the school environment, from the full development of the personality through educating and emancipatory education. In this sense, the deductive method aims to understand the bergsonian relationship between memory and body, the formation of social behaviors by habit and the use of biopower in the diversion of education-formation to education-training, in the control society and validation of the hypothesis that the culture of peace would be a positive instrument for opening space to rational perception and clothed with affectation and intuition.
\end{abstract}

KEYWORDS: Memory-body. Biopower. Violence. Intuition. Culture of peace.

\footnotetext{
* Mestranda em Ciências Jurídicas pelo Centro Universitário de Maringá. Graduada em Direito pela Universidade Estadual de Maringá. giovanna_back@hotmail.com

** Pós-doutor em Direito Educacional pela Pontifícia Universidade Católica de São Paulo (2001). Doutor em Direito das Relações Sociais pela Pontifícia Universidade Católica de São Paulo (2000). Mestre em Direito das Relações Sociais pela Pontifícia Universidade Católica de São Paulo (1998). Graduado em Direito pela Universidade Estadual de Maringá (1996). Professor permanente do Programa de Mestrado em Ciências Jurídicas do Centro Universitário de Maringá. ivan.iddm@ gmail.com
} 


\section{INTRODUÇÃo}

A partir da análise de estudos cognitivos para compreensão da gênese de comportamentos agressivos e violentos, como o de Henri Bergson, compreende-se a plena formação do indivíduo dada não só no aspecto racional, mas especialmente pelo aspecto afetivo e intuitivo. A partir da disseminação de valores como a solidariedade, a cooperação e a paz, pela cultura da paz, estar-se-ia estabelecendo um ambiente saudável para as relações interpessoais, cujos comportamentos não estariam decalcados pelo hábito da agressividade ou marcados pela violência do controle social, mas fomentados pela capacidade criativa e intuitiva do indivíduo. Justifica-se o presente estudo na sociedade atual em que os casos de violência estão mais alarmantes, trazendo grandes consequiências nefastas aos aspectos da personalidade humana, especialmente quando se trata de violência na escola e em indivíduos em formação de sua individualidade.

A hipótese levantada pelo trabalho é a de que a sociedade atual, por meio de políticas públicas, como a cultura da paz, tem trabalhado no sentido de reduzir os fatores determinantes para a expressão de comportamentos agressivos e violentos, ao promover um ambiente pacífico, em que as potencialidades dos seres humanos possam ser desenvolvidas da melhor forma possível. Para cumprir o objetivo desejado, buscar-se-á compreender a relação "memória-corpo", na perspectiva de Henri Bergson e a noção do "decalque" de comportamentos por meio do hábito, de Deleuze, relacionando a formação do indivíduo à memória coletiva.

Posteriormente, investigar-se-á a ontogenia do comportamento da agressividade e a importância do ambiente para o desencadeamento dos instintos agressivos, dando ênfase ao ambiente capitalista e a noção foucaultiana de biopoder, responsável pelo disciplinamento dos corpos pelo reforço do hábito, inclusive no ambiente escolar.

Por derradeiro, verificar-se-á a eficácia da implementação da cultura da paz na educação como mecanismo para a minimização da repetição do hábito e fomento da percepção intuitiva, a fim de impedir as condutas violentas, oriundas da agressividade, no ambiente escolar. 
Além disso, analisar-se-á a perspectiva foucaultiana sobre o modelo educacional, fundamentado no biopoder, e a tendência da sociedade de controle de regular não só os corpos, mas também as almas e consciências, através das redes de relacionamento interpessoal e da repetição do hábito, conjuntura essa combatida pela cultura da paz e educação em direitos humanos.

\section{CULTURA DA PAZ E EDUCAÇÃO EM DIREITOS HUMANOS}

A cultura da paz, segundo Leila Maria Torraca de Brito (2014, p. 132-133), é "uma proposta contínua e permanente de responsabilidade de todas as disciplinas e, certamente, da instituição escolar. Uma educação que contemple aspectos intelectuais e morais, e valores". Com a interiorização desses valores, haveria estímulos ao pensamento crítico, adequado à sociedade democrática. A autora ainda destaca que, a educação para a paz, envolve a mudança de valores, comportamentos e atitudes individuais e coletivas, promovidas, principalmente, por políticas públicas, a cargo de vários atores sociais, mas, especialmente, a instituição escolar.

Seria um caminho para a construção da paz duradoura, proposta por Imannuel Kant, visto que "a paz é conseguir a reconciliação das vítimas e dos algozes, de tal modo que ambos voltem à vida normal que tanto desejam, recobrem seu domínio interior e seu sentido de dignidade" (GÓMEZ, 2001, p. 16).

Segundo Rafael Trentin Scremin (2014, p. 40), a cultura da paz oscila entre ações possíveis, como a mediação ou a conciliação para a solução de conflitos, e situações abstratas, que extrapolam a racionalidade, como o equilíbrio e a harmonia. De qualquer forma, não é compreendida apenas como a ausência de guerras, mas como a possibilidade de realização de valores, em um constante desafio de compreensão do outro.

Essa cultura tem como ícones o norueguês Johan Galtung e o espanhol Xésus Jares que, sob influência dos estudos de John Dewey e Paulo Freire, compreendem sua fundamentação no conceito de paz positiva e na perspectiva criativa do conflito (JARES, 2007, p. 31). E mais, diz respeito à educação em direitos humanos, a partir de pressupostos democráticos, como a mediação escolar (abrange a perspectiva criativa do conflito como elemento agregador e articulador do processo educativo), e da compreensão crítica da realidade circundante, visto que a escola é o espaço de discussão qualificada para transformação do indivíduo e para o pleno desenvolvimento da personalidade. 
Essa personalidade, no entanto, pode ser significativamente afetada pela violência. Tendo-se em vista que as contradições da sociedade capitalista alimentam as estruturas fundadoras da violência, é preciso compreender as estruturas e as formas de violência que, na escola, não é fenômeno isolado, mas parte de um contexto mais amplo. Não há violência escolar, como gênero, mas a violência que se pratica na escola, a partir de uma realidade externa. No entanto, não é o espaço que determina a violência, mas esta se apropria do espaço, diante da desorganização do corpo coletivo e dos valores sociais, produzindo a sociabilidade do medo, a banalização da violência e o uso desta para solução de conflitos (MOCCHI, 2013, p. 137-140).

Aliás, tratando-se de violência na escola, como o Bullying, estar-se-á falando de crianças e adolescentes, indivíduos em formação da personalidade e da construção dos seus alicerces. Ressalta-se que o bullying, nessa faixa etária da infância e adolescência, ocorre quando o cérebro não está totalmente formado, de modo que o impacto dessa forma de violência deixa cicatrizes neurobiológicas e psicológicas profundas, podendo levar a sérios danos na relação e convívio entre os pares (COELHO, et al, 2012, p.87). Há, portanto, grande prejuízo na integridade emocional e no pleno desenvolvimento do indivíduo, além de afetar outros componentes da personalidade em formação.

Na perspectiva da educação para a paz, portanto, é fundamental que se tenha a escola como centro difusor de valores e atitudes, dando azo à função socializadora para o enfrentamento de problemas. Porém, a construção desse ambiente propício deve ser coletiva, tendo em vista a corresponsabilidade entre Estado, família e sociedade para a garantia da educação, conforme previsto no artigo 205, da Constituição Federal da República do Brasil e no inciso VI, do artigo 12 da Lei de Diretrizes e Bases da Educação Nacional (lei 9.394/96).

Dessa forma, estar-se-á em um ambiente que abre possibilidades para que se iniba a repetição inconsciente da memória do hábito, que se torna regra para o biopoder, e seja proporcionado um espaço para a percepção consciente, fruto da razão e do espírito. Ou seja, essa forma de educação não deve servir de instrumento de moldagem de corpos, a serviço do biopoder, que atua muito mais na dimensão espiritual que na dimensão corpórea, mas deve ser um meio de solução de conflitos, além de transformação do indivíduo e do pleno desenvolvimento da personalidade.

Acredita-se, por essa perspectiva, que, podendo resolver pacificamente seus conflitos, haja vista valores sociais cooperativos, promovidos pela cultura da paz nas escolas, os 
indivíduos não abrirão espaço à entrada da violência e serão capazes de lidar com a memória habitual da agressividade. Em um ambiente pacífico, poderão, pela educação, desenvolver sua personalidade e suas capacidades. É nesse sentido que a educação para a paz atuaria para a salvaguarda dos elementos inerentes à personalidade humana.

Deve-se estar atento, porém, para que esse movimento pedagógico, focado na educação em direitos humanos, seja uma educação-formação e não uma educaçãotreinamento, que induz ao fortalecimento da ideia coletiva sufocando a individualidade e, quando técnica-operacional, nega a formação crítica e humanística, visto que não está isenta de valores, que podem ser cooptados para interesses específicos (BITTAR, 2007, p. 314).

Nesse sentido, Foucault alerta sobre os instrumentos da educação de adestramento dos indivíduos, que controlam o ser humano enquanto espécie, no intuito de interiorizar comportamentos de integração, e de consequente exclusão. É possível, portanto, com a educação-treinamento, instrumentalizar a sociedade de controle, visto que assim a escola ultrapassaria os limites institucionais e exerceria controle sobre outras esferas, como a família e a sociedade (PANIAGO; FERNANDES, 2013, p.70). Essa seria a atuação do biopoder, que se desmaterializa e se torna fluido nas redes flexíveis de controle.

Dessa maneira, a educação para a paz, quando utilizada de forma técnica-operacional de formação acrítica e, portanto, desviada de sua missão da educação para os direitos humanos em nome de interesses específicos da sociedade de controle, torna-se um mecanismo de controle que interioriza valores adequados ao poder de comando, por um discurso dissimulador de liberdade, que adestra e disciplina os corpos, tornando-os dóceis e úteis aos objetivos do poder.

Veiga-Neto (2003, p. 140) defende que na sociedade de controle houve uma mudança de ênfase, frente à sociedade disciplinar, desempenhando importante papel nos processos de subjetivação, penetrando não apenas nos corpos a serem domesticados, mas na consciência, a fim de controlar a totalidade das ações humanas, tornando-se totalmente biopolítico.

Para o controle também da alma, valoriza-se a repetição, pois "é através dela que se acredita que determinadas atitudes serão incorporadas permanentemente no comportamento do indivíduo" (PANIAGO; FERNANDES, 2013, p. 72). Essa forma de atuação frente à violência não deixa de ser uma violência, só que invisível, “[...] sem necessitar de armas, violências físicas, coações materiais." (FOUCAULT, 2000, p. 218), que ao invés de expandir o conhecimento para além do hábito, reforça-o no disciplinamento do corpo e do espírito, e 
abre espaço ao instinto da agressividade, como forma de resistência e sobrevivência a essa máquina opressora do biopoder.

Sendo, no entanto, aplicada de forma democrática e emancipatória, sem a mera repetição de formas, a educação para a paz é mais que acumulação de conhecimento, é reflexão, dúvida e desdobramento de ideias simples (TERNES, 2004, p. 164), i.e., a instrumentalização de mudanças, por meio da sensibilidade e da humanidade (LAGO; MOTTA, 2010, p. 47). Assim, é preciso a constante recriação e intuição criativa bergsoniana, desmistificando as figuras tradicionais da escola, para que a autonomia ou maioridade, propostas por iluministas como Kant, não criem atalhos para a submissão e a normalização de corpos dóceis e úteis.

Aliás, para melhor compreender a (re)criação e a intuição criativa bergsoniana, que pode ser utilizada eficazmente pela educação da paz, é imprescindível a compreensão da relação memória-corpo, traçada por Bergson, e a noção de do hábito de comportamentos, marcados pelo decalque, que acaba sendo utilizado no modelo educacional vigente, que privilegia a educação-treinamento, sufocando a função instrucional da educação voltada ao pleno desenvolvimento da personalidade, em nome de interesses classistas.

\section{RELAÇÃO MEMÓRIA-CORPO-ESPÍRITO}

No que tange à questão da memória, várias são as dimensões possíveis de análise, tais como: psicológica, coletiva, existencial (ontológica) ou histórica. No presente trabalho, porém, o estudo sobre o referido objeto será realizado a partir de uma perspectiva coletiva e histórica. Nesta, a co-relação entre corpo e memória está na habituação do corpo a comportamentos sociais em uma relação utilitarista de sobrevivência. O hábito é, portanto, uma forma de memória implícita, adquirida pela repetição ou, conforme os ensinamentos de Deleuze (1995), pelo "decalque".

Gilles Deleuze trabalha a questão da representação a partir da noção de construção de mapas, que constroem estruturas abertas à reversão e à adaptação, e da noção de decalque. Neste, o produto que se obtém é uma imagem estática e cristalizada, destacando-se que [...] O decalque age como um modelo, enquanto o mapa age como um processo, revertendo o modelo e criando sua estrutura. Trata-se, então, de um modelo que se entranha, e do processo que se alonga, rompe e retoma" (NEVES, 2008, p. 6). 
Nesse sentido, Gilles Deleuze e Félix Guattari desenvolvem o método rizomático para compreensão da representação da realidade. Para eles, a diferença entre os indivíduos possibilita um constante processo de criação, a partir das relações múltiplas por essência, o que denominam de "devir". No entanto, esta representação, dada pelo ato de mapear, processo criativo de invenção e de expansão da potência de vida, não é a única forma de representação, há também o decalque, que não mais produz, mas reproduz e propaga redundâncias (FERREIRA, 2008, p. 31-37).

Isso está relacionado a uma perspectiva social da construção da memória, trazida por Halbwachs (2006), na qual a construção individual da memória se dá a partir da memória coletiva da sociedade. Desse modo, existe uma relação da memória com os acontecimentos dos espaços sociais. Assim, a percepção ou apreensão sobre o mundo real ocorre a partir da memória social gravada ou "decalcada" no indivíduo, realizando a relação entre matéria e espírito, em consonância com os ensinamentos de Bergson (1999).

A verdadeira memória, portanto, remontaria não só às experiências individuais, mas às experiências da espécie humana, pautada nas reminiscências da memória coletiva que está incrustada nos seres humanos, realizada pela constante re-elaboração do passado no presente, combinando a percepção ao espírito (GUIMARÃES, et.al., 2012).

É importante destacar que Bergson (1999) defende que a memória não estaria nas cognições cerebrais, mas no espírito do indivíduo, embora ele destaque que existem diferentes formas de conhecimento e, consequentemente, formas de ação, visto que o ser humano é formado por uma dimensão pragmática e outra intuitiva; uma voltada à sobrevivência, outra, à capacidade criativa.

Através da repetição motora, o indivíduo adquire a memória do hábito, ao passo que é por intermédio da intuição, presente no âmbito do espírito, marcada pela afetação da realidade sobre o corpo (imagem central) e pelas sensações, que se desenvolve o agir criativo, permeado de valores. A tendência do espírito é a evolução criativa, a partir de um processo de transformação e de transcendência.

O corpo seria, portanto, a imagem percebida externamente, pelas percepções, e internamente pelas afeições, havendo profunda relação entre os estímulos, também chamados de imagens, oriundos da realidade e os movimentos ou agir do ser humano, escolhidos voluntariamente conforme os interesses e as vantagens.

Bergson (1999) ainda destaca: 
[...] não há percepção que não esteja impregnada de lembranças. Aos dados imediatos e presentes de nossos sentidos, misturamos milhares de detalhes de nossa experiência passada. Na maioria das vezes, estas lembranças deslocam nossas percepções reais, das quais não retemos então mais que algumas indicações, simples "signos" destinados a nos trazerem à memória antigas imagens.

Ou seja, a percepção ocorre a partir de memórias de experiências passadas e de forte subjetividade individual. Por meio da percepção se realiza a representação da matéria em imagens. Contudo, menciona que existem dois tipos de percepção. A primeira, holística e inconsciente, é apreendida pela afetação que causa no corpo; a segunda, parcial e consciente, é a que passa pelo filtro do discernimento, moldado pelas experiências passadas, e que determina a ação ou movimento do corpo.

No que tange à memória do hábito, esta se diferencia da percepção na medida em que não depende de reflexão frente ao estímulo, isto é, não depende do discernimento frente à imagem, mas da repetição motora. Dessa forma, distancia-se do espírito e das afeições ou afetações para sua apreensão, de tal maneira que pode se afirmar que existe uma relação intrínseca entre a memória e o espírito.

Dessa maneira, para Bergson (1999), a memória é agente na criação das subjetividades individuais a partir das relações do corpo com a realidade que o cerca. O passado pode ser estático, mas as experiências e os hábitos reflexos do passado são dinâmicos, podendo sempre se atualizar, pois o que se armazena não é o passado, mas os reflexos e as percepções dele.

\subsection{Hábito da agressividade}

Dentre as formas de conhecimento e representação propostas por Bergson, dar-se-á destaque nesse trabalho ao hábito ou costume, intrinsecamente vinculado ao instinto natural ou tendência mecânica, para a busca de alimento, para ataque ou para defesa do grupo social e/ou da prole, que se forma a partir da repetição de experiências semelhantes.

O hábito seria, portanto, a condição natural do fenômeno cognitivo, por utilizar "a experiência passada para iluminar a experiência presente" (RODRIGUES, 2017, p. 84), sendo considerado por Bergson como um princípio para explicação do conhecimento prático e teórico, a partir das regularidades do mundo.

Essas representações da realidade, juntamente com a percepção, são mapeadas, de forma rizomática, quando se tratam de cognições criativas, ou decalcadas, quando se trata de 
hábito, no espírito do indivíduo, tendo em vista a memória coletiva herdada para a sobrevivência da espécie, estruturando a ação individual.

Bergson trata de uma forma da gênese da cognição humana, destacando a importância da sensibilidade e do entendimento, os quais têm o interesse prático ou a ação em comum. "É sempre uma estrutura da ação que está por trás de todas as atitudes teóricas da inteligência, de todas as operações intelectuais, de todas as condutas do ser percipiente" (RODRIGUES, 2017, p. 91).

O papel do hábito na vida prática está na orientação, na utilidade e na eficácia da ação, tendo em vista os objetos da experiência, a partir da apreensão de conceitos gerais, alicerçados em abstrações e generalizações, pelo método indutivo. O conceito abstrato, representado intelectualmente, somente poderá se fazer presente após a reflexão dedutiva, cabendo frisar que os hábitos estarão presentes inclusive no domínio do conhecimento puro.

Somada a essa concepção da formação da memória, cumpre mencionar a importância da ontogenia do comportamento, a qual remete à agressividade como um mecanismo biologicamente construído para o ataque e a fuga, diante da adversidade. O comportamento social, portanto, seria formado por estímulos e se propagaria na presença de estímulos e, apenas se isso implicar vantagem seletiva (DORNELLES, 2012, p. 57).

Portanto, tanto o ambiente quanto a memória social, podem contribuir para o comportamento agressivo, corroborando com a tese de Bergson de que o contexto social ou âmbito material, como o estresse ou maus-tratos, além do perfil socioeconômico desvantajoso, interage com fatores imanentes ao indivíduo, como o espírito, de modo a favorecer a expressão de comportamentos, dentre eles, os agressivos.

Dá-se destaque, nesse ponto, ao ambiente com baixo investimento parental na afetividade e com maior dificuldade de sobrevivência, por haver baixo poder socioeconômico e cultural, o qual, segundo Vinícius Guimarães Dornelles (2012, p. 77), favoreceria o florescimento de comportamentos agressivos.

A agressividade é, portanto, uma reação natural, formada desde os tempos mais remotos da história humana, que pode estar relacionada inclusive à linguagem como reação na dialética (MOCCHI, 2013, p. 115) e pode ser, até certa medida, controlada pela racionalidade. Por sua vez, a violência não é um comportamento instintivo e compulsivo, mas uma ação intencional de negação da alteridade alheia e a objetificação da vida humana, reduzida a mero instrumento para o alcance de fins específicos (RUIZ, 2014, p. 32). 
Em outras palavras, a violência não é inata ao ser humano, porém ocupa espaço quando a natureza humana age fora da racionalidade devido a uma intenção predeterminada de negar o outro, que viola a personalidade alheia, por violar a integridade e a dignidade humana (MOCCHI, 2013, p. 118).

Quando há, portanto, ruptura do nexo social e negação da interação social pela comunicação, encontra-se terreno fértil à propagação da violência, tanto na macro sociedade quanto na micro sociedade escolar. Esta é reflexo daquela, por não ser uma ilha imune à realidade que a cerca, somada à ausência do cumprimento de sua função de aprendizagem e vivência. Assim, o ambiente que deveria ser de diálogo, alteridade e construção da personalidade, torna-se espaço de prática da violência.

É importante compreender, porém, que Bergson perfilha de uma concepção que conecta a biologia às questões de filosofia política, a qual legitima a violência como um dado natural do ser humano, de modo a naturalizá-la e compreendê-la como um elemento não só da sociedade, mas da potência de vida (RUIZ, 2014, p. 16). Nesse aspecto, segundo Arendt (1985, p. 145), há uma confusão conceitual entre violência, poder, potência, autoridade e força; embora utilizados como sinônimos, refletem distintas realidades, de maneira que a concepção bergsoniana sobre a violência pode ser considerada insuficiente e reducionista, por não considerar a racionalidade instrumental da violência utilizada pelo poder em suas tecnologias de controle sobre as subjetividades (FOUCAULT, 2008, p. 141) e por se tornar um meio útil para legitimação da barbárie (ARENDT, 1985, p. 101).

E é essa camada de racionalidade instrumental que dá azo à "violência estrutural que instrumentaliza a vida humana como mero elemento natural” (RUIZ, 2014, p. 29), movido pelas necessidades biológicas e pelos instintos. Essa violência é o biopoder, o qual administra os desejos e gerencia utilitariamente as liberdades (FOUCAULT, 1999, p. 134).

\section{HABITUAÇÃO DOS CORPOS PELO BIOPODER}

Michel Foucault, em "Microfísica do Poder" trouxe a proximidade entre a concepção de memória e a historicidade do sujeito, a fim de combinar o poder da disciplina e a biopolítica com a força do hábito, o qual garante que o indivíduo que produz é simultaneamente produzido, o que é chamado de "biopoder". 
Para Foucault, tanto o corpo, imagem bersoniana, quanto o sujeito, podem ser contextualizados historicamente, aproximando-se da concepção de memória histórica, proposta por Halbwalchs (2006, p. 73). O autor defende que o poder da disciplina e da biopolítica, combinado com a força do hábito, produz o indivíduo e modela seus corpos para efetivação da gestão política sobre as populações. É o que ele chama de "biopoder", ou "poder sobre a vida", que atua sobre a relação entre a memória e o corpo, trabalhando o hábito, para reforçar a função utilitarista dos corpos.

Os corpos são disciplinados e adestrados com a finalidade de aumentar a aptidão econômica do indivíduo e, simultaneamente, reduzir a potência política, na medida em que separa o produto da força de trabalho, alienando o ser humano (FOUCAULT, 2009, p. 133). Cumpre destacar que a disciplina não ocorre tão somente pela repressão, mas também pela produção de desejos e saberes sobre o corpo, e é o dispositivo foucaultiano do biopoder, por meio do qual as relações humanas, mesmo em suas representações inconscientes, além da relação do indivíduo com o mundo e consigo mesmo, são fabricadas em nome do pressuposto da ordem "natural” (GUATTARI; ROLNIK, 1996, p.42).

O ser humano, como mencionado, é tratado e manipulado como máquina, visando à docilidade e subjugação ao sistema de produção. Assim, reduz-se a atuação do espírito na execução das ações volitivas do indivíduo e adestra-se o corpo, em seu aspecto racional, inteligível e obediente à práxis (FOUCAULT, 2009).

Várias são as instituições mencionadas por Foucault para o exercício do biopoder na produção do ser humano moderno, imbuídas por procedimentos técnicos de normalização e controle voltados ao melhor uso do tempo e do espaço, mas dá-se destaque no presente trabalho às instituições escolares. Por qualquer delas "o corpo assume, gradativamente, o papel de objeto e alvo do poder" (RODRIGUES, Luís Carlos, 2017, p. 57).

Em outras palavras, o biopoder, na perspectiva de Foucault, reforça a função pragmática do hábito sobre os corpos, visto que os corpos são produzidos a partir das relações de poder. Para esse fim, utiliza-se, principalmente, da escola, como instituição de produção do indivíduo adequado à sociedade burguesa, através de procedimentos técnicos de normalização e controle, garantindo a perpetuação da "cultura burguesa".

O modelo burguês do "homem moderno" é reproduzido, então, pelas escolas e sua disciplina (no contexto da educação-treinamento), visto que dociliza corpos e os torna úteis à população ao valorizar a memória do hábito em prol de resultados. O hábito é, portanto, 
reforçado pela docilidade e utilidade na escola, de maneira que a produção passa do nível individual ao coletivo e os indivíduos repetem o mesmo, afastando-se de qualquer possibilidade do novo e promovendo o individualismo (RODRIGUES, Luís Carlos, 2017, p. 70). Soma-se a isso que, no contexto do capitalismo, o ser humano compete diuturnamente com a sua própria espécie por vários motivos, como recursos, espaço e até pela sobrevivência.

A lógica, impregnada na relação memória-corpo, é a da competitividade, em virtude da eficiência e da eficácia, que ultrapassa a sobrevivência e resgata os instintos de agressividade e solução de conflitos de forma irracional, resgatando a memória humana coletiva "decalcada". Para tanto, o papel da escola não tem sido mais o de formação integral do indivíduo (MOCCHI, 2013), mas instrumento de legitimação dos interesses e da transmissão do estilo de vida da classe dominante ou de ideologias minoritárias.

Como outros direitos historicamente conquistados, a educação está vinculada ao momento histórico em que se desenvolveu. Na Grécia Antiga, era instrumento de transformação do indivíduo, per si e como ente social, e aprimoramento da vida política, noção esta que foi resgatada na Baixa Idade Média e na Modernidade, mas acrescida da concepção de meio para garantir a utilidade e a eficiência da vida laboral, ou seja, à profissionalização (MOCCHI, 2013).

Qualificação profissional é proposta entre os objetivos da educação, juntamente com o pleno desenvolvimento, no art. 205 da Constituição Federal da República do Brasil de 1988, sendo que a educação, então vista como direito social, passa a ser fundamental para o desenvolvimento do modo de produção capitalista. De modo que a educação-treinamento se tornou um discurso ideológico para transmissão de valores adequados ao capitalismo e legitimação dos interesses da classe dominante (MOCCHI, 2013, p. 90).

A importância não está mais no desenvolvimento da personalidade do indivíduo, mas no desenvolvimento da produção, de liberdades políticas e civis e da consciência nacional patriótica, sendo a educação um importante mecanismo para reprodução e perpetuação do sistema. Assim, aquele modelo educacional da Grécia Antiga, voltado à formação integral do indivíduo, tem sucumbido frente ao modelo empresarial, de prestação de serviços, reforçando a formação utilitária dos indivíduos pelo hábito, através do "decalque". E esse modelo sujeita a identidade e a individualidade do indivíduo à massificação dos corpos e comportamentos, realizando "decalques" na alma para formar matérias e aprisionar personalidades e singularidades (RODRIGUES, Luís Carlos, 2017). 
A memória escolar, juntamente com outras formas de alienação, portanto, reproduz a subjetividade capitalista, pró-ativa, e as formas de regulação social, sujeitando a identidade ao comando da massa. Perde-se, pois, a ênfase da diferença entre a multiplicidade, garantindo a padronização, ou seja, o indivíduo e a coletividade fazem parte do mesmo desejo, decalcado na alma pela repetição. (GUATTARI; ROLNIK, 1996).

O disciplinamento dos indivíduos e de suas singularidades, até pelas instituições escolares, a partir do reforço do hábito indelével da agressividade, por exemplo, reforça sobremaneira a normalidade de condutas violentas, inclusive no ambiente escolar, o que dificulta a prevenção e o combate dessas, com o objetivo de garantir a personalidade.

Assim, a violência, no sistema capitalista, como um padrão de comportamento competitivo, oculta a violência real oriunda das desigualdades sociais, das exclusões, do autoritarismo e da intolerância, fruto de uma crise no campo ético, por uma significação intencional de negar o outro. E os mecanismos ficam mais complexos pela impossibilidade de diálogo para a construção democrática da sociedade, mas a imposição do padrão de comportamento burguês de disciplinamento dos corpos, rompendo o nexo social e fabricando relações artificiais, moldadas pelo reforço do hábito.

Assim, se o contexto em que o indivíduo se desenvolve favorece o desencadeamento da agressividade e da violência, isto é, se há profunda influência do meio social para o desenvolvimento da ação violenta, é fundamental que seja criado um espaço coletivo de harmonia e desenvolvimento de valores, como o fomento à cultura da paz.

É imprescindível, portanto, que o ser humano, por meio da sua capacidade dedutiva, outrora exposta, atue além dos hábitos. Não se fala em eliminar a memória do hábito, visto que é parte importante da apreensão da realidade humana, podendo ser fonte de operações intelectuais, dado seu papel epistêmico (RODRIGUES, Paulo Cesar, 2017, p. 98). Porém, a capacidade perceptiva racional, frente às afetações, e a capacidade intuitiva é que viabilizam o pleno desenvolvimento individual.

Para tanto, a educação deve ser ativa, participativa e democrática, voltada à formação do ser humano através da promoção de vivências e valores, como a solidariedade, a tolerância, a cooperação e a paz, em vista do rompimento de paradigmas e de comportamentos decalcados na memória do indivíduo e do fomento da intuição e da capacidade criativa para a emancipação do indivíduo (SACAVINO; CANDAU, 2000, p. 44). Essa é a meta da educação para a paz, a qual atua sobre a aprendizagem cognitiva ou racional, 
mas também sobre os aspectos valorativos e afetivos que se estendem da escola para a sociedade (MOEHLECKE, 2013, p. 10), a partir dos direitos humanos e da dignidade da pessoa humana como perspectiva de base (LAGO, 2013, p. 68).

\section{CONCLUSÃO}

Existe uma complexa relação entre a memória coletiva e o corpo disciplinado na perpetuação cultural da violência, impulsionada pela competitividade e individualidade do modo de produção capitalista. Por isso, objetivou-se nesse trabalho compreender a relação bergsoniana "memória-corpo" no contexto foucaultiano do biopoder e de que maneira isso influencia a proliferação da violência, especialmente no ambiente escolar, que deveria ser de diálogo e da abertura de possibilidades.

Inicialmente, tratou-se da educação para a paz ou educação em direitos humanos, que contempla aspectos morais (valores) e intelectuais e abre possibilidades não só de solução de conflitos, como de transformação do indivíduo e de plena formação da personalidade, ao promover mudanças sociais por intermédio da sensibilidade e da humanidade. Além disso, essa forma de educação, quando voltada à formação e não ao treinamento, possibilita a inibição da repetição inconsciente da memória do hábito - instrumento do biopoder - e a promoção de um espaço para a percepção consciente do indivíduo, que contempla não só a razão, mas também o espírito.

Buscou-se, então, compreender a proposta de Bergson sobre a co-relação memóriacorpo ou matéria-espírito, a partir de uma perspectiva social da construção da memória, trazendo a noção da habituação do corpo, pelo "decalque", a comportamentos sociais úteis à sobrevivência. Há, portanto, quase que uma "simbiose" entre os aspectos imanentes do indivíduo e o ambiente que o cerca, para formação do indivíduo a partir das reminiscências da memória coletiva.

Destacou-se, também, a ontogenia do comportamento, trazendo a agressividade como um mecanismo adaptativo frente à adversidade e a violência como um instrumento das relações sociais. Logo, o ambiente favoreceria o resgate e reforço do hábito, sendo agravado no ambiente capitalista, em que o biopoder é responsável pela disciplina dos corpos, para que sejam úteis e eficientes. Nesse sentido, a subjetividade capitalista produz corpos e relações, em conformidade com o jogo de interesses econômicos e políticos, através do contínuo 
reforço do hábito, inclusive de instintos agressivos, modelo esse que pode ser reproduzido no ambiente escolar, para formação utilitária do indivíduo e legitimação de interesses.

A violência não seria, então, como a agressividade, uma reação irracional frente aos conflitos, fruto da memória implícita de comportamentos "decalcada" na cultura humana, mas uma ação intencional de negação da alteridade alheia e a objetificação da vida humana, reduzida a mero instrumento para o alcance de fins específicos. Ou seja, um mecanismo de ocultação da violência real e da crise no campo ético diante da ausência de diálogo e de uma construção democrática da sociedade pela imposição de um padrão de corpos e comportamentos, através do biopoder.

$\mathrm{Na}$ perspectiva foucaultiana, conclui-se que essa educação, quando voltada ao treinamento e não à formação, pode ser essencialmente de controle, não só do corpo, mas da alma, com a interiorização de valores e comportamentos, fundamentais à utilidade e à eficiência desses indivíduos no âmbito social, sob um pretenso pretexto de liberdade. Seria, pois, a biopolítica atuando sobre o comportamento individual, docilizando-o e tornando-o padronizado.

Tendo isso em vista, trouxe-se a hipótese de que a educação para a paz, com a pacífica resolução de conflitos, traz a possibilidade de um ambiente propício ao desenvolvimento das potencialidades do indivíduo, por limitar os fatores ambientais de expressão da agressividade e da violência, que atentam contra a personalidade, especialmente de indivíduos em formação, e possibilitar a defesa e a promoção dos direitos inerentes ao ser humanos.

Para a cultura da paz, o papel da escola estaria adstrito, além da instrução e da profissionalização, conjuntamente com a família e o Estado, à difusão de valores para o enfrentamento de problemas sociais. Essas funções da escola estariam vinculadas a um espaço destinado à percepção consciente, forma de conhecimento complementar ao hábito (ferramenta do biopoder), destinada à transformação do ser humano pela percepção - fruto do discernimento - e pela intuição criativa.

\section{REFERÊNCIAS}

ARCHER, John. The nature of human aggression. In: International Journal of Law and Psychiatry, n. 32, v.4, 2009, p. 202-208. 
ARENDT, Hannah. Da violência. Trad. Maria Cláudia Drummond. Brasília: Ed. da Universidade de Brasília, 1985.

BERGSON, Henri. Matéria e memória. Trad. Paulo Neves. 2 a ed. São Paulo: Martins Fontes, 1999.

BITTAR, Eduardo Carlos Bianca. Educação e metodologia para os direitos humanos: cultura democrática, autonomia, ensino jurídico. In: SILVEIRA, Rosa Maria Godoy, et al. Educação em Direitos Humanos: Fundamentos teórico-metodológicos. João Pessoa: Editora Universitária, 2007, p. 313-334.

BRITO, Leila Maria Torraca de. Bullying e cultura de paz no advento da nova ordem econômica. Rio de Janeiro: EDUERJ, 2014.

COELHO, Roberta Paula Schell; et al. Neurobiologia do bullying. p. 87-96. In: DORNELLES, Vinícius Guimarães, et.al. Bullying: avaliação e intervenção em terapia cognitivo-comportamental. Porto Alegre: Sinopsys editora, 2012.

DELEUZE, Gilles; GUATTARI, Félix. Mil platôs: capitalismo e esquizofrenia. V.1. São Paulo: Editora 34, 1995.

Bergsonismo. São Paulo: Editora 34, 1999.

DORNELLES, Vinícius Guimarães, et.al. Bases genéticas evolucionistas do comportamento social agressivo. p. 55-86. In: DORNELLES, Vinícius Guimarães, et.al. Bullying: avaliação e intervenção em terapia cognitivo-comportamental. Porto Alegre: Sinopsys editora, 2012.

FERREIRA, Flávia Turino. Rizoma: um método para as redes? In: Liinc em revista, v.4, n.1, mar./2008. Rio de Janeiro, p. 28-40.

FOUCAULT, Michel. História da sexualidade: a vontade de saber. Rio de Janeiro: Graal, 1999.

. Microfísica do poder. Rio de Janeiro: Graal, 2000.

. Segurança, território e população. São Paulo: Martins Fontes, 2008.

. Vigiar e punir. 36.ed. Rio de Janeiro: Petrópolis Editora, 2009.

GÓMES, Leonel Narváez. A reconciliação: para prevenir a violência e construir a paz duradoura. Seminário de cultura da paz e prevenção da violência no Rio de Janeiro e Belo Horizonte. 16 a 19 de outubro de 2001.

GUATTARI, Félix; ROLNIK, Suely. Micropolítica: cartografias do desejo. 4.ed. Petrópolis: Ed. Vozes, 1996. 
GUIMARÃES, Joaquim Francisco Soares, et.al. O conceito de memória na obra "Matéria e memória" de Henri Bergson. VI Colóquio Internacional "Educação e Contemporaneidade". São Cristóvão, SE, set. 2012.

HALBWACHS, Maurice. A memória coletiva. São Paulo: Centauro, 2006.

JARES, Xésus. Educar para a paz em tempos difíceis. São Paulo: Palas Athena, 2007.

LAGO, Andrea Carla Moraes Pereira. Direito educacional: prevenção da violência e solução de conflitos pela mediação escolar. Maringá-PR: IDDM, 2013.

LAGO, Andrea Carla Moraes Pereira; MOTTA, Ivan Dias da. Mediação escolar: educando para a paz. Encontro Nacional do CONPEDI; 09-12 jun. 2010; Fortaleza-CE.

MOCCHI, Cássio Marcelo. A violência na escola: no âmbito do direito educacional e seus reflexos nos direitos da personalidade. Maringá, PR: IDDM Editora, 2013.

MOEHLECKE, Sabrina. Direitos humanos e educação. In: Direitos humanos e educação: salto para o futuro. Ano XVIII, mar./abr., 2008, p. 3-20.

NEVES, Heloísa. O mapa [ou] um estudo sobre representações complexas. In: Re[dobra], v. 1, n.5, 2008. Disponível em: http://www.corpocidade.dan.ufba.br/arquivos/mapa.pdf. Acesso em: 03 de dezembro de 2018.

PANIAGO, Maria de Lourdes Faria dos Santos; FERNANDES, Eliane Marquez da Fonseca. O corpo educado: a escola como dispositivo disciplinador na sociedade de controle. In: Revista Eletrônica de Estudos do Discurso e do Corpo. Vitória da Conquista, v.2, n.2, p. 6877, 2013.

RODRIGUES, Luís Carlos. A relação memória e corpo na educação física: uma experiência do PIBID-FURB. Maringá: IDDM Editora, 2017.

RODRIGUES, Paulo César. O papel do hábito na constituição da cognição: Bergson leitor de Hume? In: Dois pontos: Revista dos departamentos de filosofia da Universidade Federal do Paraná e da Universidade Federal de São Carlos. Curitiba; São Carlos, v. 14, n. 2, dez. /2017, p. 83-108.

RUIZ, Castor M. M. Bartolomé. Poder, violência e biopolítica: diálogos (in)devidos entre H. Arendt e M. Foucault. Veritas, v. 59, n. 1, jan./abr.2014, p. 10-37.

SACAVINO, Suzana Beatriz; CANDAU, Vera Maria. Educar em direitos humanos: construir democracia. Rio de Janeiro: DP\&A, 2000.

SCREMIN, Rafael Trentin. Cultura da paz e educação: simbolismo, racionalidade e práxis. Curitiba: Editora CRV, 2014. 
TERNES, José. Foucault e a educação: em defesa do pensamento. In: Revista Educação e Realidade, v. 29, n. 1, jan/jun, 2004, p. 155-168.

VEIGA-NETO, Alfredo. Foucault e a educação. Belo Horizonte: Autêntica, 2003. 